\title{
Sense of Coherence, Self-Disclosure, and Depression in Lung Cancer Patients
}

\author{
Constantinos Togas, Fotios Anagnostopoulos, George Alexias \\ Department of Psychology, Panteion University of Social and Political Sciences, Athens, Greece \\ Email: togascostas@yahoo.gr
}

How to cite this paper: Togas, C., Anagnostopoulos, F. and Alexias, G. (2021) Sense of Coherence, Self-Disclosure, and Depression in Lung Cancer Patients. Open Journal of Medical Psychology, 10, 11-26. https://doi.org/10.4236/ojmp.2021.101002

Received: September 27, 2020

Accepted: January 26, 2021

Published: January 29, 2021

Copyright (c) 2021 by author(s) and Scientific Research Publishing Inc. This work is licensed under the Creative Commons Attribution International License (CC BY 4.0).

http://creativecommons.org/licenses/by/4.0/ (cc) (i) Open Access

\begin{abstract}
This study aimed to investigate the relationship between sense of coherence and depression and the mediating role of self-disclosure in lung cancer patients. A cross-sectional study was conducted in "Sotiria" Chest Diseases Hospital, Greece, with a sample of 200 lung cancer patients. The administered questionnaires included demographic-medical information, SOC-13, Distress Disclosure Index, and CES-D scale. Analysis was performed by SPSS v.23 and PROCESS. Depression was common (41\%) and negatively correlated to SOC (rho $=-0.843, \mathrm{df}=198, \mathrm{p}<0.001)$, while self-disclosure did not mediate this relationship. Hierarchical linear regression analysis showed that patients with weak SOC, disease recurrence, metastases, low income, and receiving therapy in Day clinic had higher levels of depression. In conclusion, a strong SOC represents a protective factor against depression in lung cancer patients. Consequently, there is a need for targeted interventions, which should mainly increase SOC of these patients.
\end{abstract}

\section{Keywords}

Lung Cancer, Sense of Coherence, Self-Disclosure, Depression, Quantitative Method

\section{Introduction}

Lung cancer is the second most common type of cancer in modern western societies (about $14 \%$ of all new cancers) and the leading cause of death from cancer in both sexes [1]. Apart from the biological dimension of the disease, especially important is the psychosocial one, and lung cancer patients have increased rates of psychological distress when compared to patients with other cancers [2] [3].

There are two main histological types, non-small cell lung cancer (NSCLC; approximately $85 \%-90 \%$ of lung cancers) and small cell lung cancer (SCLC; 
about $10 \%-15 \%$ of lung cancers), with the latter having worse prognosis and quality of life [1]. Moreover, the lungs are commonplace for metastases of cancer that start in other organs (e.g., breast, colon, bladder, etc). Approximately two of three patients diagnosed with lung cancer are over 65 years old, and the average age at the time of diagnosis is about 71 years [1]. The five-year survival rate of lung cancer is very low ( $18 \%$ in the USA and $12.6 \%$ in Europe) [4]. These patients present high rates of comorbidity (e.g., chronic pulmonary disease, diabetes) and are aware of their poor prognosis. This may be associated with an increased risk of depression [5].

The prevalence of depression in lung cancer patients is high in a percentage of $11 \%-44 \%$ [6] [7]. This wide range of prevalence rates may occur because of the various research methodologies used (i.e., cross-sectional or prospective studies) and the various questionnaires administered in different studies. Other reasons may be non-standard cut-off scores for the diagnosis of depression, differences in sampling method and reliability of the instruments, non-homogeneity of the samples (outpatients or hospitalized patients), differences in cultural contexts, etc. In a Japanese study, the percentage of patients with depression (evaluated by the Hospital Anxiety and Depression Scale) was $12.4 \%$ [8]. In the USA, Zabora, BrintzenhofeSzoc, Curbow, Hooker, and Piantadosil examined patients with 14 cancer types using the Brief Symptom Inventory and the prevalence of psychological distress (including depression) in lung cancer patients was 43.4\% [9].

Similar percentages of depressed patients with NSCLC (46.1\%) were found by Shi, Gu, Hou et al. in China [10], while smaller percentages were reported by Margari et al. [11] (21.8\%) and Rolke et al. (14\%) [6]. The percentage of those with depression (evaluated using the Hospital Anxiety and Depression Scale) among Chinese patients with first diagnosed lung cancer was $27.7 \%$, while in another study in newly diagnosed lung cancer patients in Italy, $44.2 \%$ suffered from moderate or severe depression, as evaluated using Zung Self-Rating Depression Scale [12] [13].

Researchers have suggested various risk factors for developing depression in lung cancer patients, but these factors have been examined separately with relatively small samples [8]. Risk factors include underlying personality traits (e.g., neuroticism), younger age, female sex, low income, lesser educational attainment, and single marital status [6] [8] [14] [15].

Patients with SCLC have an increased risk of depression compared with patients with NSCLC. The advanced stage of the disease, poor social functioning, unhealthy behaviors (e.g., alcohol intake, smoking), and physical symptoms following cancer (e.g., pain, dyspnea) have been suggested as risk factors for depression in these patients, too [7] [8]. Metastases and relapse have also been suggested as risk factors for depression in cancer patients [16].

Apart from the demographic and medical characteristics, several personality traits (e.g., Sense of Coherence) and communication with the social environment (e.g., self-disclosure) have also been related to depression in lung cancer patients. The aim of this study was to examine the relationship between sense of 
coherence, self-disclosure, and depression in these patients after controlling the effects of background variables. The elucidation of the relation among these variables is essential due to the epidemiological data regarding lung cancer and the high prevalence of psychological symptoms (especially depressive symptomatology) in these patients. Identification of these relations is expected to contribute to the development of a set of proposals about the achievement of better mental health outcomes for lung cancer patients.

Unlike many other types of cancer, lung cancer is usually associated with a behavioral etiology (smoking). As a result, these patients often perceive that they are stigmatized for their disease and may seek to conceal their diagnosis [2] [17]. Self-disclosure, as a process of communication by which one person reveals information (thoughts, feelings, etc.) about himself to another, has also been associated with improved mental health and decreased symptoms of depression [18]. On the other hand, concealing distressing personal information predicts negative well-being, while reluctance to express emotions is related to heightened psychological symptoms [19] [20]. Concerning cancer patients, self-disclosure refers to a situation in which they openly discuss their diagnosis, in terms of thoughts and feelings about their disease [21]. One of the most challenging aspects of having cancer is to disclose the diagnosis to others [22]. Many researchers agree that self-disclosure is beneficial to cancer patients, while other researchers argue against this assumption [23] [24].

Adaptation to cancer is also associated with a patient's ability to consider it as a challenge and to believe that he can manage it. Antonovsky's sense of coherence (SOC) theory constitutes an interesting explanation of how patients adjust to their disease [25]. Sense of coherence is "a global aspect, which expresses the degree in which people have a continual, intense and dynamic sense of self-confidence that 1 ) the incentives from their internal and external environment are structured, anticipated and explainable (comprehensibility), 2) they have the ability to manage the demands that derive from these incentives (manageability) 3) these demands are challenges, that is worth for them to deal with them (meaningfulness)" [26]. Consequently, SOC makes a person capable of managing the distress, recognizing the internal and external support factors, promoting efficient coping, and solving the distress in a way that promotes mental health [27]. SOC develops during childhood and early adulthood, and after that, it is only affected in a minor way by major life events [26]. However, several studies have shown that interventions can influence SOC levels [28].

There is a positive association between SOC and perceived mental health and a negative one between SOC and perceived stressful events and depression [25] [29]. Moreover, SOC may be useful for predicting the onset of depression and identifying persons at high risk for future depression [30].

Only a few investigations have examined the sense of coherence in cancer patients and even fewer in lung cancer patients. SOC in cancer patients is slightly weaker than the general population. Patients' age and duration of the disease 
may be positively related to SOC, while there are no differences according to gender, race, or educational level [31]. In a study with cancer patients, those with strong SOC reported fewer depressive symptoms than those with weaker SOC [32]. In Rolke's et al. study with lung cancer patients, weak SOC was only slightly (but significantly) associated with depression [6].

Although depression in lung cancer patients has been examined in many studies, the investigation of the association between SOC, self-disclosure, and depression is a relatively neglected area of research. This study linked these three variables together by testing the associations among SOC, self-disclosure, and depression and examining the mediating role of self-disclosure to further explore the development of depressive symptoms. According to the authors' knowledge, this is one of the few studies investigating if SOC would be related to depression in lung cancer patients and whether self-disclosure could mediate this relationship.

Based on the theoretical principles of Antonovsky's Sense of Coherence theory, it was hypothesized that: 1) lower levels of SOC would be associated with higher levels of depression (Hypothesis 1), 2) depression would be significantly related to SOC and disclosure, taking into account the effects of demographic (gender, age) and medical variables (histological type of cancer, metastases, recurrence, etc.) (Hypothesis 2), 3) self-disclosure would mediate the relationship between SOC and depression in these patients (Hypothesis 3).

\section{Methods}

\subsection{Procedure}

A cross-sectional study was conducted with a convenience sample of 200 lung cancer patients in the Oncology Unit and the outpatient clinic of the 3rd Department of Athens University School of Medicine (which specializes in cancer treatment) in "Sotiria" Chest Diseases Hospital, Athens, Greece. "Sotiria" is one of the largest specialized hospitals in Greece, and patients from all over the country are being treated in it. The research was conducted in this hospital in order to achieve a representative database. The duration of the study was 17 months. The sample consisted of patients who came to the Day clinic and outpatient clinic, based on the daily program of these units. Patients were coming to the day clinic in order medication to be prescribed, to get chemotherapy and to be further examined. These patients completed the questionnaires before their therapy. Patients who had completed their treatment visited the outpatient clinic for follow-up and completed the questionnaires after their examination. All patients were seen in the waiting room.

The sample consisted of diagnosed lung cancer patients regardless of histological type and staging. Patients with secondary lung cancer, severe psychiatric symptoms, and those who could not participate due to their impaired health status (as it was ascertained by the doctors or the medical records) were excluded. 
A composite questionnaire was used, including sociodemographic data, information about the medical history and Sense of Coherence (SOC-13) Scale, Distress-Disclosure Index, and Center for Epidemiologic Studies-Depression Scale (CES-D). Before approaching the patients, the researcher asked the doctors or nurses if they were informed (fully or partially) about their diagnosis. The sociodemographic data were completed during the interview, and the information about the medical history was taken later from the individuals' medical records and the hospital's files. Since most of the sample participants were old and either illiterate or only had a primary school level of education, the questionnaires were completed by interview.

\subsection{Sample}

According to the eligibility criteria, 222 patients were selected to participate in the study, and 200 of them accepted (response rate: 91\%). Non-participation was mainly due to time constraints. The majority of the participant were old (Mean age: 69.54 years, SD: 8.21 , Min: 48, Max: 91, Range: 43 ), and the mean time since diagnosis was 13.5 months (Min: 1, Max: 60, Range: 59). Demographic and medical characteristics of the sample are presented in Table 1.

Table 1. Demographic and medical characteristics of the sample $(\mathrm{N}=200)$.

\begin{tabular}{|c|c|c|}
\hline & $\mathbf{N}$ & Percentage (\%) \\
\hline \multicolumn{3}{|l|}{ Gender } \\
\hline Men & 141 & $70.5 \%$ \\
\hline Women & 59 & $29.5 \%$ \\
\hline \multicolumn{3}{|l|}{ Age group } \\
\hline$<65$ years & 63 & $31.5 \%$ \\
\hline $65-74$ years & 87 & $43.5 \%$ \\
\hline$\geq 75$ years & 50 & $25 \%$ \\
\hline \multicolumn{3}{|l|}{ Marital status } \\
\hline Single & 10 & $5 \%$ \\
\hline Married & 162 & $81 \%$ \\
\hline Divorced & 13 & $6.5 \%$ \\
\hline Widow/widower & 15 & $7.5 \%$ \\
\hline \multicolumn{3}{|l|}{ Educational level } \\
\hline Illiterate-Primary school & 108 & $54 \%$ \\
\hline Secondary school & 44 & $22 \%$ \\
\hline Lyceum & 34 & $17 \%$ \\
\hline Higher education & 9 & $4.5 \%$ \\
\hline \multicolumn{3}{|l|}{ Income status } \\
\hline High & 16 & $8 \%$ \\
\hline Adequate & 135 & $67.5 \%$ \\
\hline Low & 49 & $24.5 \%$ \\
\hline
\end{tabular}




\section{Continued}

Setting of service provision

Day clinic

Outpatient clinic

Histological type

NSCLC

SCLC

Knowledge about diagnosis

Yes

No

Smoking

Yes

No

Therapy (during the study or earlier)

\begin{tabular}{|c|c|}
\hline Radiotherapy (as monotherapy) & 1 \\
\hline Chemotherapy (as monotherapy) & 105 \\
\hline Combination of radiotherapy-chemotherapy & 40 \\
\hline Combination of chemotherapy-surgical Resection & 41 \\
\hline $\begin{array}{l}\text { Combination of radiotherapy-chemotherapy- } \\
\text { Surgical resection }\end{array}$ & 13 \\
\hline
\end{tabular}

Metastases (in brain, bones, liver, etc.).

$\begin{array}{lcc}\text { Yes } & 49 & 24.5 \% \\ \text { No } & 151 & 75.5 \%\end{array}$

Recurrence during last month

Yes

20

$10 \%$

No

180

$90 \%$

\subsection{Measures}

Sense of Coherence Scale-13 (SOC-13). It assesses all three SOC basic components: comprehensibility (e.g., "Are you surprised by the behaviour of people whom you thought you knew well?"), manageability (e.g., "How often do you have feelings that you're not sure you can keep under control?") and meaningfulness (e.g., "How often do you have the feeling that there's little meaning in the things you do in your daily life?" [33]. The total score ranges from 13 to 91, and higher scores indicate stronger SOC. Its Greek version has adequate psychometric properties [34], and in the present study, Cronbach's alpha coefficient was equal to 0.93 .

Distress-Disclosure Index: It consists of 12 questions, which measure a person's tendency to disclose personally unpleasant information in various situations (e.g., "When I feel upset, I usually confide in my friends"). The total score ranges from 0 to 36 , and higher scores indicate a greater tendency to disclose 
psychological distress [35]. The Greek translation of the scale was used in the present study [36], and Cronbach's alpha coefficient was equal to 0.97 .

Center for Epidemiologic Studies-Depression Scale (CES-D): It detects the levels of depression in the general population. It includes 20 questions about the depressive symptoms during last week divided into six categories: depressive mood, sense of guilt and incompetency, despair, psychomotor slow-down, loss of appetite, sleep disorders [37]. The total score ranges from 0 to 60 , and higher scores indicate higher rates of depression. The cut-off score to discriminate between normal and psychopathological states is 16 [37]. Its Greek version has adequate psychometric properties [38], and in the present study, Cronbach's alpha coefficient was equal to 0.94 .

\subsection{Data Analysis}

Data analysis was performed using SPSS v.23.0. The Kolmogorov-Smirnov test was used to examine the normality of continuous variables. The analysis included descriptive statistics and Spearman's correlation coefficient to examine linear correlations among quantitative variables. Mann-Whitney and Kruskal-Wallis tests were used to check statistically significant differences between two or more groups, correspondingly. Non-parametric tests were used because of the non-normal distribution of the data. Moreover, a hierarchical multiple linear regression analysis and a simple mediation analysis using PROCESS were performed [39]. Statistical significance level (p-value) was set to $5 \%$.

\subsection{Ethics}

Approval was sought from the hospital's Research and Ethics Committee, which was granted. Signed informed consent was obtained from all research participants. All patients took part on a voluntary basis and were not remunerated for their participation. They were given assurance of anonymity and confidentiality of the information provided and was informed that they could stop completing the questionnaire at any time if they wished. They were also assured that the collected data would be used only for the purpose of the study and that their decision to withdraw would not compromise the standards of the care provided.

\section{Results}

Descriptive statistics for the questionnaires (SOC-13, Self-Disclosure Index, CES-D) are presented in Table 2.

Table 2. Descriptives for main psychological variables $(N=200)$.

\begin{tabular}{lccccc}
\hline & Mean & SD & MIN & MAX & Range \\
\hline 1) SOC & 58.00 & 15.58 & 25 & 83 & 58 \\
2) Self-Disclosure & 16.80 & 10.35 & 0 & 36 & 36 \\
3) Depression & 22.34 & 11.78 & 1 & 53 & 52 \\
\hline
\end{tabular}


A score of 16 or higher on CES-D scale has been extensively used as the cut-off point suggesting clinical depression [37]. If this value is used as the cut-off point, then $58.5 \%$ of lung cancer patients would suffer from depression. However, if the value of 23/24 is used as the cut-off point (which has been suggested as optimal for the Greek version of the CES-D), then $41 \%$ of the patients would show depression [38].

A statistically significant negative correlation was found between SOC and CES-D score (rho $=-0.843, \mathrm{df}=198, \mathrm{p}<0.001)$ and Self-Disclosure Index and CES-D score ( $r h o=-0.586, \mathrm{df}=198, \mathrm{p}<0.001)$. SOC was positively correlated with self-disclosure $($ rho $=0.618, \mathrm{df}=198, \mathrm{p}<0.001)$.

Following the above findings, a hierarchical linear regression analysis was performed. Demographic characteristics, medical information, self-disclosure, and SOC were entered as predictor variables in blocks 1,2,3, and 4, respectively, and depression was the outcome variable. The blocks were included in the model separately. No evidence of multicollinearity among the variables was suggested given tolerance levels over 0.1 and VIF (Variance Inflation Factor) values under 10. In addition, no evidence of outliers or influential points was suggested after the examination of Mahalanobis and Cook distances, Centered Leverage Value and Dffits, and DfBetas. The results of the hierarchical regression analysis are presented in Table 3.

Table 3. Hierarchical linear regression with depression as the dependent variable.

\begin{tabular}{|c|c|c|c|c|c|c|c|c|}
\hline Predictor & $B$ & $S E B$ & $\beta$ & $\begin{array}{l}95 \% \mathrm{CI} \\
\text { (Confidence } \\
\text { Interval) }\end{array}$ & $R^{2}$ & $\begin{array}{l}\text { Adjusted } \\
\qquad \mathbf{R}^{2}\end{array}$ & $\begin{array}{l}\text { R Square } \\
\text { Change }\end{array}$ & F Change \\
\hline Step 1 & & & & & 0.14 & 0.12 & 0.14 & $6.15^{\star *}$ \\
\hline $\begin{array}{l}\text { Gender } \\
\qquad \text { Men }^{* * *} \text { versus Women }\end{array}$ & 4.95 & 1.93 & 0.19 & {$[1.15,8.75]$} & & & & \\
\hline Age & -0.03 & 0.11 & -0.02 & {$[-0.24,0.18]$} & & & & \\
\hline $\begin{array}{l}\text { Marital status } \\
\qquad \text { Married }^{* * *} \text { versus single-divorced-widowler }\end{array}$ & 1.08 & 1.41 & 0.05 & {$[-1.70,3.85]$} & & & & \\
\hline $\begin{array}{l}\text { Educational level } \\
\text { Illiterate-Primary/ secondary school }{ }^{* * *} \text { versus } \\
\text { Lyceum/higher education }\end{array}$ & -1.81 & 0.80 & $-0.17^{\star}$ & {$[-3,38,-0.24]$} & & & & \\
\hline $\begin{array}{l}\text { Income status } \\
\qquad \text { Low }^{* * *} \text { versus adequatel high }\end{array}$ & 9.84 & 3.05 & $0.23^{* *}$ & {$[3.87,15.9]$} & & & & \\
\hline Step 2 & & & & & 0.31 & 0.26 & 0.17 & $6.29^{\star *}$ \\
\hline $\begin{array}{l}\text { Gender } \\
\qquad \text { Men }^{* * *} \text { versus women }\end{array}$ & 3.36 & 1.88 & 0.13 & {$[-0.36,7.07]$} & & & & \\
\hline Age & -0.09 & 0.10 & -0.06 & {$[-0.29,0.11]$} & & & & \\
\hline $\begin{array}{l}\text { Marital status } \\
\text { Married }^{* * *} \text { versus Single-divorced-widow/er }\end{array}$ & 0.65 & 1.32 & 0.03 & {$[-1.95,3.25]$} & & & & \\
\hline $\begin{array}{l}\text { Educational level } \\
\text { Illiterate-Primary/secondary school }{ }^{* * *} \text { versus } \\
\text { Lyceum/higher education }\end{array}$ & -1.49 & 0.74 & $-0.14^{*}$ & {$[-2.95,-0.04]$} & & & & \\
\hline
\end{tabular}




\section{Continued}

\begin{tabular}{|c|c|c|c|c|c|c|c|c|}
\hline $\begin{array}{l}\text { Income status } \\
\qquad \text { Low }^{* * *} \text { versus adequate/ high }\end{array}$ & 9.42 & 2.81 & $0.22^{\star *}$ & {$[3.87,14.94]$} & & & & \\
\hline Months elapsed since diagnosis & -0.08 & 0.08 & -0.08 & {$[-0.23,0.07]$} & & & & \\
\hline $\begin{array}{l}\text { Setting of service provision } \\
\text { Day Clinic }{ }^{* * *} \text { versus Outpatient Clinic }\end{array}$ & -3.70 & 2.26 & -0.11 & {$[-8.16,0.76]$} & & & & \\
\hline $\begin{array}{l}\text { Smoking } \\
\quad \text { Smoking } \\
\end{array}$ & -2.02 & 2.39 & -0.06 & {$[-6.73,2.70]$} & & & & \\
\hline $\begin{array}{l}\text { Information (Knowledge) about diagnosis } \\
\text { Informed (fully-partially) }{ }^{* * *} \text { versus not informed }\end{array}$ & 4.15 & 3.37 & 0.08 & {$[-2.51,10.80]$} & & & & \\
\hline $\begin{array}{l}\text { Histological type } \\
\qquad N S C L C^{* * *} \text { versus } S C L C\end{array}$ & 1.82 & 1.51 & 0.08 & {$[-1.16,4.81]$} & & & & \\
\hline $\begin{array}{l}\text { Recurrence } \\
\quad \text { Having recurrence }{ }^{* * *} \text { versus not having recurrence }\end{array}$ & -7.95 & 2.65 & $-0.20^{\star *}$ & {$[-13.18,-2.72]$} & & & & \\
\hline $\begin{array}{l}\text { Metastases } \\
\quad \text { Having metastases }{ }^{* * *} \text { versus not having metastases }\end{array}$ & -6.70 & 1.79 & $-0.25^{\star *}$ & {$[-10.24,-3.17]$} & & & & \\
\hline Step 3 & & & & & 0.54 & 0.50 & 0.23 & $89.82^{\star *}$ \\
\hline $\begin{array}{l}\text { Gender } \\
\qquad \text { Men }^{* * *} \text { versus women }\end{array}$ & 4.09 & 1.55 & $0.16^{\star *}$ & {$[1.04,7.15]$} & & & & \\
\hline Age & -0.07 & 0.08 & -0.05 & {$[-0.23,0.10]$} & & & & \\
\hline $\begin{array}{l}\text { Marital status } \\
\qquad \text { Married }^{* * *} \text { versus Single-divorced-widow/ er }\end{array}$ & -0.20 & 1.08 & -0.01 & {$[-2.33,1.94]$} & & & & \\
\hline $\begin{array}{l}\text { Educational level } \\
\text { Illiteratel Primary/ secondary school }{ }^{* * *} \text { versus } \\
\text { Lyceum/ higher education }\end{array}$ & -0.33 & 0.62 & -0.03 & {$[-1.55,0.89]$} & & & & \\
\hline $\begin{array}{l}\text { Income status } \\
\qquad \text { Low }^{* * *} \text { versus adequate/ high }\end{array}$ & 8.44 & 2.31 & $0.19^{\star *}$ & {$[3.89,12.99]$} & & & & \\
\hline Months elapsed since diagnosis & -0.03 & 0.06 & -0.03 & {$[-0.15,0.09]$} & & & & \\
\hline $\begin{array}{l}\text { Setting of service provision } \\
\text { Day Clinic }{ }^{* * *} \text { versus Outpatient Clinic }\end{array}$ & -5.00 & 1.86 & $-0.15^{\star *}$ & {$[-8.67,-1.34]$} & & & & \\
\hline $\begin{array}{l}\text { Smoking } \\
\quad \text { Smoking } \\
\end{array}$ & -1.87 & 1.96 & -0.05 & {$[-5.74,1.99]$} & & & & \\
\hline $\begin{array}{l}\text { Information (Knowledge) about diagnosis } \\
\text { Informed (fully-partially) }{ }^{* * *} \text { versus not informed }\end{array}$ & 2.49 & 2.77 & 0.05 & {$[-2.97,7.96]$} & & & & \\
\hline $\begin{array}{l}\text { Histological type } \\
\qquad N S C L C^{* * *} \text { versus } S C L C\end{array}$ & 1.23 & 1.24 & 0.052 & {$[-1.22,3.68]$} & & & & \\
\hline $\begin{array}{l}\text { Recurrence } \\
\quad \text { Having recurrence }{ }^{* * *} \text { versus not having recurrence }\end{array}$ & -6.44 & 2.18 & $-0.17^{\star *}$ & {$[-10.74,-2.14]$} & & & & \\
\hline $\begin{array}{l}\text { Metastases } \\
\quad \text { Having metastases }{ }^{* * *} \text { versus not having metastases }\end{array}$ & -4.74 & 1.48 & $-0.17^{\star *}$ & {$[-7.66,-1.81]$} & & & & \\
\hline Self-Disclosure & -0.58 & 0.06 & $-0.51^{\star *}$ & {$[-0.70,-0.46]$} & & & & \\
\hline Step 4 & & & & & 0.80 & 0.79 & 0.26 & $238.73^{\star *}$ \\
\hline $\begin{array}{l}\text { Gender } \\
\qquad \text { Men }^{* * *} \text { versus women }\end{array}$ & -0.50 & 1.06 & -0.02 & {$[-2.58,1.60]$} & & & & \\
\hline Age & -0.05 & 0.06 & -0.02 & {$[-0.14,0.07]$} & & & & \\
\hline $\begin{array}{l}\text { Marital status } \\
\quad \text { Married }^{* * *} \text { versus single-divorced-widow/er }\end{array}$ & 0.63 & 0.71 & 0.03 & {$[-0.78,2.04]$} & & & & \\
\hline
\end{tabular}




\section{Continued}

\begin{tabular}{|c|c|c|c|c|}
\hline lucational level & & & & \\
\hline $\begin{array}{l}\text { Illiterate-Primary/ secondary school }{ }^{* * *} \text { versus } \\
\text { Lyceum/higher education }\end{array}$ & -0.14 & 0.41 & -0.01 & {$[-0.94,0.66]$} \\
\hline $\begin{array}{l}\text { Income status } \\
\qquad \text { Low }^{* * *} \text { versus adequatel high }\end{array}$ & 3.28 & 1.55 & $-0.08^{\star}$ & {$[0.21,6.34]$} \\
\hline Months elapsed since diagnosis & -0.06 & 0.04 & -0.06 & {$[-0.15,0.02]$} \\
\hline $\begin{array}{l}\text { Setting of service provision } \\
\text { Day Clinic } \\
\text { (** versus Outpatient Clinic }\end{array}$ & -3.07 & 1.23 & $-0.09^{* *}$ & {$[-5.49,-0.65]$} \\
\hline $\begin{array}{l}\text { Smoking } \\
\quad \text { Smoking }{ }^{* * *} \text { versus no smoking }\end{array}$ & 0.31 & 1.30 & 0.01 & {$[-2.25,2.87]$} \\
\hline $\begin{array}{l}\text { Information (Knowledge) about diagnosis } \\
\text { Informed (fully-partially) }{ }^{* * *} \text { versus not informed }\end{array}$ & -0.06 & 1.83 & -0.01 & {$[-3.67,3.55]$} \\
\hline $\begin{array}{l}\text { Histological type } \\
\qquad N S C L C^{* * *} \text { versus } S C L C\end{array}$ & 0.72 & 0.82 & 0.03 & {$[-0.89,2.33]$} \\
\hline $\begin{array}{l}\text { Recurrence } \\
\quad \text { Having recurrence }{ }^{* * *} \text { versus not having recurrence }\end{array}$ & -4.79 & 1.44 & $-0.12^{\star *}$ & {$[-7.63,-1.96]$} \\
\hline $\begin{array}{l}\text { Metastases } \\
\quad \text { Having metastases }{ }^{* * *} \text { versus not having metastases }\end{array}$ & -2.78 & 0.98 & $-0.10^{\star *}$ & {$[-4.72,-0.84]$} \\
\hline Self-Disclosure & -0.10 & 0.05 & -0.09 & {$[-0.20,0.01]$} \\
\hline Sense of coherence & -0.56 & 0.04 & $-0.73^{\star *}$ & {$[-0.63,-0.49]$} \\
\hline
\end{tabular}

Note. ${ }^{*} \mathrm{p}<0.05 ;{ }^{* *} \mathrm{p}<0.01 ;{ }^{* *}$ Reference category.

The results showed that SOC was negatively associated with depression $\left(b^{*}=\right.$ $-0.73)$. Moreover, patients with low-income status $\left(b^{*}=-0.08\right)$, who had metastases $\left(b^{*}=-0.10\right)$, disease recurrence during last month $\left(b^{*}=-0.12\right)$ and were receiving treatment in the Day clinic $\left(b^{*}=-0.09\right)$ had higher levels of depression compared to those who had adequate/good income status, had not metastases and recurrence and were examined in the outpatient clinic. Self-disclosure was also negatively associated with depression, and this relationship approached statistical significance $(p=0.053)$. The proportion of variance in depression accounted for by all independent variables was equal to $79 \%$. The best predictor variable of depression in the model was sense of coherence, followed by recurrence during last month, metastases, place of therapy/examination (Day clinic versus outpatient clinic), and income status (bad versus adequate/good).

According to simple mediation analysis (Figure 1) there was a significant negative direct effect $(\mathrm{p}<0.001)$ of Sense of Coherence on depression (as measured by CES-D). We also tested the indirect effect of SOC on depression through self-disclosure. This path was nonsignificant ( $b=-0.035,95 \%$ BCa CI: [-0.0833, 0.0099]).

\section{Discussion}

This study aimed to assess the relationships between sense of coherence, self-disclosure, and depression in a sample of lung cancer patients in Greece and 


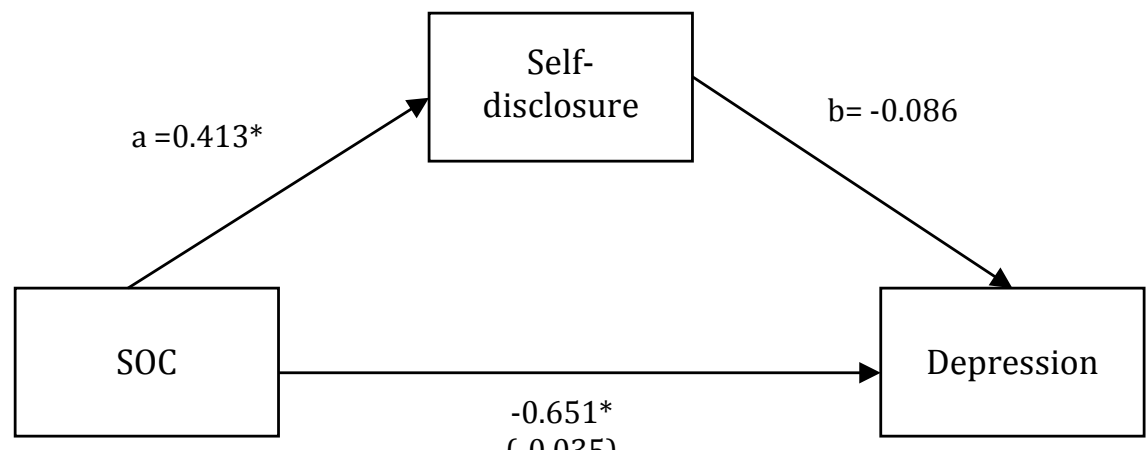

$(-0.035)$

Figure 1. Path diagram of the simple mediation model: self-disclosure as a mediator between SOC and depression. Note: Standardized coefficients $(\beta)$ are presented. ${ }^{\star} \mathrm{p}<0.001$.

explore the relationship between depression and sociodemographic and medical variables. The literature review suggested that very few studies had examined the relationships between these variables in lung cancer patients, and this fact highlights the novelty of the present study.

The main results of this research indicated that depression was common in Greek lung cancer patients, that there was a negative correlation between SOC and depression, while self-disclosure did not mediate this relationship. Furthermore, depression was significantly related to SOC (but not to self-disclosure), after controlling for the effects of demographic and medical variables (gender, age, histological type of cancer, etc.). Consequently, hypothesis 1 was confirmed, hypothesis 2 was partially confirmed, and hypothesis 3 was not confirmed.

The results show that the prevalence of depression in Greek patients with lung cancer is high (41\%), at least compared to the general population of Greece, where the percentage of depression is 5.7\% [40]. Numerous other studies have shown that the prevalence of depression in lung cancer patients is high [6] [7] [9] [10] [12] [13].

There was a significant negative correlation between sense of coherence and depression. This means that the stronger the patient's sense of coherence is, the less depressed he/she is. This result is consistent with that of other studies, in which SOC was found to correlate strongly and negatively with perceived depression in cancer patients [32].

Thus, sense of coherence was associated with reduced levels of depression among these patients. It seems likely that a strong SOC represents a protective factor, not only the absence of current depression [28]. Possible mechanisms behind this association can be identified in several ways. A strong SOC has been shown to be related to a lower rating of stress for several life events, fewer reports of having stressful events, less emotional distress, and a lower level of anxiety [30]. In addition, higher SOC makes the situation with cancer more comprehensible, manageable, and meaningful and enables patients to achieve more control of the situation and feel safe [41]. As a result, SOC protects patients from depression.

There was also a significant negative correlation between self-disclosure and 
depression. This result is consistent with that reported by Uysal et al. [19]. It seems that self-disclosure decreases the likelihood that negative feelings will become more complicated and intense and increases the instrumental assistance available from the social environment [42]. In addition, self-disclosure can help people work through their difficulties, while concealing of distressing information or a reluctance to express emotions may predict low well-being and heightened psychological symptoms [19] [20] [22]

The results of the hierarchical linear regression analysis showed that SOC was negatively related to depression. Moreover, patients with low income, who had recurrence during last month and were receiving therapy in day clinic had higher levels of depression compared to those who had high/adequate income and had no recurrence and were examined in the outpatient clinic. Low income has been found to be a risk factor for depression in other studies, too [15]. Self-disclosure was not found to be a significant predictor variable in the hierarchical linear regression model, but its relationship with depression approached statistical significance.

Finally, patients who had metastases had higher levels of depression than those who had not metastases, a finding similar to that reported in other studies [16] [43]. These findings are explained by the better health status that implies the absence of recurrence and metastases and the examination in the outpatient clinic. Gender, marital status, level of education, and duration of the disease were not significantly associated with depression, as opposed to findings of other studies [6] [8] [10] [14]. These non-similar findings may be due to differences in sample characteristics, type of lung cancer, questionnaires administered, and cultural context of the several countries. Mediation analysis revealed that self-disclosure did not significantly mediate the association between SOC and depression. However, the direct effect of SOC on depression was significant. These findings may be explained by the fact that the distress-disclosure index evaluates general self-disclosure and not the disclosure of the disease-specific feelings and may indicate that therapeutic interventions should mainly increase SOC.

The primary advantage of this study is that the topic examined covers a large gap in the literature and provides evidence and information that can be used by mental health practitioners who work therapeutically with lung cancer patients. Furthermore, the prevalence of lung cancer in modern times demonstrates its importance in everyday clinical practice.

As for current research limitations, it must be highlighted that this is a cross sectional study, in which it is not possible to examine causal relations. Furthermore, the stage of the disease was not recorded in some patients (because there was a need for restaging the disease or this information did not exist in the medical records), so this variable was not evaluated. In addition, as other researchers have reported, diagnosis of depression in cancer patients is difficult because treatments (e.g., chemotherapy) often result in many of the symptoms needed for a diagnosis of depression, such as fatigue, weight loss, loss of appetite, or sleep disruption 
and psychomotor retardation. These symptoms (apart from weight loss) were also evaluated by CES-D in this study. As such, it is difficult to determine with reasonable accuracy the source of these symptoms, and the depression among cancer patients is often underestimated or overestimated [44]. Consistent with these reports, several patients in the present study misinterpreted some questions of the CES-D questionnaire and reported, e.g., sleeping problems, which were not caused by depression but mainly by dyspnoea, a predominant symptom of lung cancer. This probably resulted in false-positive rates of depression and might explain, to some extent, the high rates of depression found in this survey. Moreover, waiting for medical examinations may have affected the answers given to the questionnaire items, e.g., patients might be more anxious or pessimistic than usual. Finally, a psychiatric interview in order to verify the results regarding depression was not used.

Notwithstanding the limitations discussed above, the results of this research are useful to make suggestions for supportive care and counseling of lung cancer patients. The percentage of depression in lung cancer patients is very high. However, oncologists usually do not diagnose depressed patients and do not refer them to a mental health professional [45]. It is, therefore, necessary to recognize the vulnerable patients (according to the identified risk factors) and to implement interventions for their psychological support. In addition, the application of Sense of Coherence theory in lung cancer may be valuable, and its evaluation could be a basic standard of their care. Psychologists could also address interventions to strengthen the SOC (comprehensibility, manageability, meaningfulness) of their patients and protect them from depression. Consequently, the study of sense of coherence can expand our knowledge about the mental state of these patients and may contribute to the development of models of care [46].

Future research is suggested so that further investigation and clarification of the study's results to be possible. It would be beneficial to carry out a longitudinal survey to overcome the limitations of a cross-sectional study. Moreover, similar research could be conducted with a larger sample and comparison with patients with other types of cancer, in order to identify possible differences. Surveys could also focus on patients with particular needs and characteristics, e.g., patients with high comorbidity, who were never smokers, etc.

\section{Conflicts of Interest}

The authors declare no conflicts of interest regarding the publication of this paper.

\section{References}

[1] American Cancer Society (2018). http://www.cancer.org/cancer/lungcancer/index

[2] Cataldo, J.K. and Brodsky, J.L. (2013) Lung Cancer Stigma, Anxiety, Depression and Symptom Severity. Oncology, 85, 33-40. https://doi.org/10.1159/000350834 
[3] Key, G. (2015) Psychiatric Care of Lung Cancer Patients. Cancer Network, 29, 195-197.

http://www.cancernetwork.com/oncology-journal/psychiatric-care-lung-cancer-pati ents

[4] European Lung Foundation (2018)

http://www.erswhitebook.org/chapters/lung-cancer

[5] Walker, J., Sawhney, A., Hansen, C.H., Symeonides, S., Martin, P., Murray, P. and Sharpe, M. (2013) Treatment of Depression in People with Lung Cancer: A Systematic Review. Lung Cancer, 79, 46-53. https://doi.org/10.1016/j.lungcan.2012.09.014

[6] Rolke, H.B., Bakke, P.S. and Gallefoss, F. (2008) Health Related Quality of Life, Mood Disorders and Coping Abilities in an Unselected Sample of Patients with Primary Lung Cancer. Respiratory Medicine, 102, 1460-1467. https://doi.org/10.1016/j.rmed.2008.04.002

[7] Hopwood, P. and Stephens, R.J. (2000) Depression in Patients with Lung Cancer: Prevalence and Risk Factors Derived from Quality-of-Life Data. Journal of Clinical Oncology, 18, 893-903. https://doi.org/10.1200/JCO.2000.18.4.893

[8] Shimizu, K., Nakaya, N., Saito-Nakaya, K., Akechi, T., Yamada, Y., Fujimori, M., Ogawa, A., Fujisawa, D., Goto, K., Iwasaki, M., Tsugane, S. and Uchitomi, Y. (2012) Clinical Biopsychosocial Risk Factors for Depression in Lung Cancer Patients: A Comprehensive Analysis Using Data from the Lung Cancer Database Project. Annals of Oncology, 23, 1973-1979. https://doi.org/10.1093/annonc/mds061

[9] Zabora, J., BrintzenhofeSzoc, K., Curbow, B., Hooker, C. and Piantadosi, S. (2001) The Prevalence of Psychological Distress by Cancer Site. Psychooncology, 10, 19-28. https://doi.org/10.1002/1099-1611(200101/02)10:1<19::AID-PON501>3.0.CO;2-6

[10] Shi, Y., Gu, F., Hou, L.L. and Hu, Y.Q. (2015) Self-Reported Depression among Patients with Non-Small Cell Lung Cancer. Thoracic Cancer, 6, 334-337. https://doi.org/10.1111/1759-7714.12179

[11] Margari, N., Karapoulios, D., Getsios, I., Rizou, V., Kostopoulou, S., Balodimou, Chr. and Siagouli, M. (2016) Anxiety and Depression in Lung Cancer Patients. International Journal of Caring Sciences, 9, 308-313.

[12] Buccheri, G. (1998) Depressive Reactions to Lung Cancer Are Common and Often Followed by a Poor Outcome. European Respiratory Journal, 11, 173-178. https://doi.org/10.1183/09031936.98.11010173

[13] Mou, Q.Q., Yu, C.H. and Li, J.Y. (2016) Investigation and Analysis for Impact Factors of Distress in Patients with First Diagnosed Lung Cancer. Journal of Peking University, 48, 507-514.

[14] Abhishekh, H.A., Balaji, A.L. and Mehta, R.M. (2014) Depression in Lung Cancer Patients. Indian Journal of Psychiatry, 56, 307.

https://doi.org/10.4103/0019-5545.140667

[15] Hung, M.S., Chen, I.C., Lee, C.P., Huang, R.J., Chen, P.C., Tsai, Y.H. and Yang, Y.H. (2017) Incidence and Risk Factors of Depression after Diagnosis of Lung Cancer: A Nationwide Population-Based Study. Medicine (Baltimore), 96, e6864. https://doi.org/10.1097/MD.0000000000006864

[16] Aass, N., Fosså, S.D., Dahl, A.A. and Moe, T.J. (1997) Prevalence of Anxiety and Depression in Cancer Patients Seen at the Norwegian Radium Hospital. European Journal of Cancer, 33, 1597-604. https://doi.org/10.1016/S0959-8049(97)00054-3

[17] Chapple, A., Ziebland, S. and McPheron, A. (2004) Stigma, Shame and Blame Expe- 
rienced by Patients with Lung Cancer: Qualitative Study. BMJ, 328, 1470. https://doi.org/10.1136/bmj.38111.639734.7C

[18] Ignatius, E. and Kokkonen, M. (2007) Factors Contributing to Verbal Self-Disclosure. Nordic Psychology, 59, 362-391. https://doi.org/10.1027/1901-2276.59.4.362

[19] Uysal, A., Lee Lin, H. and Kneem, R. (2010) The Role of Need Satisfaction in Self-Concealment and Well-Being. Personality and Social Psychology Bulletin, 36, 187-199. https://doi.org/10.1177/0146167209354518

[20] Barr, L.K., Kahn, J.H. and Schneider, W.J. (2008) Individual Differences in Emotion Expression: Hierarchical Structure and Relations with Psychological Distress. Journal of Social and Clinical Psychology, 27, 1045-1077.

https://doi.org/10.1521/jscp.2008.27.10.1045

[21] Yoo, G.J, Aviv, C., Levine, E.G., Ewing, C. and Au, A. (2010) Emotion Work: Disclosing Cancer. Supportive Care in Cancer, 18, 205-215. https://doi.org/10.1007/s00520-009-0646-y

[22] Munro, H., Scott, S.E., King, A. and Grunfeld, E.A. (2015) Patterns and Predictors of Disclosure of a Diagnosis of Cancer. Psychooncology, 24, 508-514.

https://doi.org/10.1002/pon.3679

[23] Dagan, M., Sanderman, R., Hoff, C., Jeroen Meijerink, W.J.H., Baas, P., van Haastert, M. and Hagedoorn, M. (2014) The Interplay between Partners' Responsiveness and Patients' Need for Emotional Expression in Couples Coping with Cancer. Journal of Behavioral Medicine, 37, 828-838. https://doi.org/10.1007/s10865-013-9543-4

[24] Mc Leod, D.L., Tapp, D.M., Moules, N.J. and Campbell, M.E. (2010) Knowing the Family: Interpretations of Family Nursing in Oncology and Palliative Care. European Journal of Oncology Nursing, 14, 93-100. https://doi.org/10.1016/j.ejon.2009.09.006

[25] Eriksson, M. and Lindström, B. (2006) Antonovsky Sense of Coherence Scale and the Relation with Health: A Systematic Review. Journal of Epidemiology and Community Health, 60, 376-381. https://doi.org/10.1136/jech.2005.041616

[26] Antonovsky, A. (1987) Unraveling the Mystery of Health: How People Manage Stress and Stay Well. Jossey-Bass Publishers, San Francisco.

[27] Antonovsky, A. (1979) Health, Stress and Coping. Jossey-Bass Publishers, San Francisco.

[28] Super, S., Wagemakers, M.A., Picavet, H.S., Verkoijen, K.T. and Koelen, M.A. (2016) Strengthening Sense of Coherence: Opportunities for Theory Building in Health Promotion. Health Promotion International, 31, 869-878.

[29] Luutonen, S., Sohlman, B., Salokangas, R.K., Lehtinen, V. and Dowrick, C. (2011) Weak Sense of Coherence Predicts Depression: 1-Year and 9-Year Follow-Ups of the Finnish Outcomes of Depression International Network (ODIN) Sample. Journal of Mental Health, 20, 43-51. https://doi.org/10.3109/09638237.2010.537401

[30] Sairenchi, T., Haruyama, Y., Ishikawa, Y., Wada, K., Kimura, K. and Muto, T. (2011) Sense of Coherence as a Predictor of Onset of Depression among Japanese Workers: A Cohort Study. BMC Public Health, 11, 205. https://doi.org/10.1186/1471-2458-11-205

[31] Bruscia, K., Shultis, C., Dennery, K. and Dileo, C. (2008) The Sense of Coherence in Hospitalized Cardiac and Cancer Patients. Journal of Holistic Nursing, 26, 286-294. https://doi.org/10.1177/0898010108317400

[32] Gustavsson-Lilius, M., Julkunen, J., Keskivaara, P., Lipsanen, J. and Hietanen, P. 
(2012) Predictors of Distress in Cancer Patients and Their Partners: The Role of Optimism in the Sense of Coherence Construct. Psychology and Health, 27, 178-195. https://doi.org/10.1080/08870446.2010.484064

[33] Antonovsky, A. (1993) The Structure and Properties of the Sense of Coherence Scale. Social Science and Medicine, 36, 725-733. https://doi.org/10.1016/0277-9536(93)90033-Z

[34] Anagnostopoulou, T. and Kioseoglou, G. (2002) Sense of Coherence Scale [In Modern Greek]. In: Stalikas, A., Triliva, S. and Roussi, P., Eds., Psychometric Tools in Greece, Ellinika Grammata, Athens, 586.

[35] Kahn, J. and Hessling, R. (2001) Measuring the Tendency to Conceal Versus Disclose Psychological Distress. Journal of Social and Clinical Psychology, 20, 41-65. https://doi.org/10.1521/jscp.20.1.41.22254

[36] Kormas, C., Karamali, G. and Anagnostopoulos, F. (2014) Attachment Anxiety, Basic Psychological Needs Satisfaction and Depressive Symptoms in University Students: A Mediation Analysis Approach. International Journal of Psychological Studies, 6, 1-10. https://doi.org/10.5539/ijps.v6n2p1

[37] Radloff, L.S. (1977) The CES-D Scale: A Self-Report Depression Scale for Research in the General Population. Applied Psychological Medicine, 1, 385-401. https://doi.org/10.1177/014662167700100306

[38] Fountoulakis, K., Iacovides, A., Kleanthous, S., Samolis, S., Kaprinis, S.G., Sitzoglou, K., Karpinis, G. and Bech, P. (2001) Reliability, Validity and Psychometric Properties of the Greek Translation of the Center for Epidemiological Studies-Depression (CES-D) Scale. BMC Psychiatry, 1, Article No. 3.

https://doi.org/10.1186/1471-244X-1-3

[39] Hayes, A.F. (2013) An Introduction to Mediation, Moderation and Conditional Process Modeling: A Regression-Based Approach. Guilford Press, New York.

[40] World Health Organization WHO (2018). http://apps.who.int/iris/bitstream/handle/10665/254610/WHO-MSD-MER-2017.2eng.pdf;jsessionid $=418324 \mathrm{ABC} 51985 \mathrm{D} 64314 \mathrm{AC} 44 \mathrm{D} 3903267$ ? sequence $=1$

[41] Drageset, J., Eide, G.E. and Hauge, S. (2016) Symptoms of Depression, Sadness and Sense of Coherence (Coping) among Cognitively Intact Older People with Cancer Living in Nursing Homes-A Mixed-Methods Study. PeerJ, 4, e2096. https://doi.org/10.7717/peerj.2096

[42] Derlega, V. and Berg, J. (1987) Self-Disclosure. Theory, Research and Practice. Plenum Press, New York. https://doi.org/10.1007/978-1-4899-3523-6

[43] Cordes, M.C., Scherwath, A., Ahmad, T., Cole, A.M., Ernst, G., Oppitz, K., Lanfermann, H., Bremer, M. and Steinmann, D. (2014) Distress, Anxiety and Depression in Patients with Brain Metastases before and after Radiotherapy. BMC Cancer, 14, 731. https://doi.org/10.1186/1471-2407-14-731

[44] Trask, P.C. (2004) Assessment of Depression in Cancer Patients. Journal of the National Cancer Institute. Monographs, 80-92. https://doi.org/10.1093/jncimonographs/lgh013

[45] Mosher, C.E., Hanna, N., Jalal, S.I., Fakiris, A.J., Einhorn, L.H., Birdas, T.J., Okereke, I., Kesler, K. and Champion, V.L. (2013) Support Service Use and Interest in Support Services among Lung Cancer Patients. Lung Cancer, 82, 162-167. https://doi.org/10.1016/j.lungcan.2013.06.020

[46] Nowicki, A. (2017) The Importance of Research on the Sense of Coherence and Acceptance of the Disease in Patients Receiving Palliative Care Due to Lung Cancer. Nursing and Palliative Care, 2, 1-2. https://doi.org/10.15761/NPC.1000141 